\title{
MOLÉCULAS Y POSTPORNO EN TESTO YONQUI. UNA LECTURA LITERARIA DE PAUL B. PRECIADO
}

\author{
Mariano Ernesto Mosquera \\ Universidad de Buenos Aires / Universidad Nacional de Tres de Febrero (Argentina) \\ marianoernestomosquera@gmail.com
}

Recibido: 16/01/2021 - Aprobado: 04/05/2021- Publicado: 30/07/2021

DOI: doi.org/10.17533/udea.lyl.n80a10

Resumen: El siguiente trabajo constituye una lectura desde los estudios literarios del ensayo experimental Testo yonqui de Paul Preciado. Ciertas zonas de esta obra pueden entenderse como un ejercicio de crónica al poner el énfasis en la problemática de la alteridad: un otro molecular (la testosterona), un otro amoroso-sexual (Virginie Despentes) y otro existencial (la muerte de su amigo Guillaume Dustan). En este sentido, argumentaremos que la productividad genérica de la obra se juega como resolución singular de la interacción entre cultura letrada y cibercultura.

Palabras clave: Paul B. Preciado; crónica; cibercultura; postporno; episteme de la información.

\section{MOLECULES AND POSTPORN IN TESTO YONQUI. A LITERARY READING OF PAUL B. PRECIADO}

Abstract: The following work constitutes a reading from the literary studies of the experimental essay Testo yonqui, by Paul Preciado. Certain areas of this work can be understood as a chronicle by emphasizing the problem of alterity: a molecular other (testosterone), a loving-sexual other (Virginie Despentes) and an existential other (the death of his friend Guillaume Dustan). In this sense, we will argue that the generic productivity of the work is played as a singular resolution of the interaction between literate culture and cyberculture.

Key words: Paul B. Preciado; chronicle; cyberculture; postporn; information episteme. 


\section{Introducción}

$\mathrm{P}$

aul B. Preciado es un teórico español especializado en teoría queer, feminismo y filosofía política contemporánea. Se doctoró en Teoría de la Arquitectura en la Universidad de Princeton y luego recibió una beca Fulbright para obtener un Máster en Filosofía Contemporánea y Teoría de Género en la New School for Social Research en Nueva York. Ha estudiado con personalidades importantes como Ágnes Heller y Jacques Derrida, además de haber publicado una serie de ensayos muy singulares que significaron un giro fundamental en los estudios de género, comenzando por Manifiesto contrasexual (2002), donde hace uso de las teorías de Michel Foucault, Judith Butler y Donna Haraway con el fin de analizar los nuevos dispositivos sexogenéricos.

Aunque su obra ensayística ha tenido un impacto considerable en la academia y el activismo al ser objeto de numerosos análisis y comentarios, escasamente se la ha trabajado en términos literarios. Y no se trata de la simple expansión de los estudios literarios a objetos liminares — como el ensayo-, aunque también sería un objetivo muy provechoso. Más bien, habría que reconocer que, en sus ensayos, en particular Testo yonqui (2014 [2008]), obra de la que nos ocuparemos en estas páginas, el trabajo literario con el lenguaje es una dimensión central, productiva, sugerente, incluso autopercibida como fundamental. Por lo que la ausencia de trabajos en este sentido resulta, como mínimo, sorprendente. Es probable que la fuerza y polemicidad de sus argumentos sobre los estudios de género hayan oscurecido y ocultado el genuino interés que su escritura, en términos literarios, puede suscitar. Para aportar en este sentido, nuestra lectura intentará demostrar que puede pensarse al ensayo de Preciado como parte de una zona de las prácticas literarias hispanoamericanas en la que se visibilizan las transformaciones genéricas de la literatura en la era digital. Así, nuestra hipótesis general es que Testo yonqui, desde los gestos de autopresentación de la textualidad hasta las formas, las matrices y los modos de tramar argumentos, constituye una resolución singular a la tensión contemporánea entre cultura letrada y cibercultura (Mendoza, 2011).

\section{Los usos posibles de una literatura híbrida}

El carácter autoconsciente de la escritura de Preciado impulsa a recorrer el modo en que el sujeto del enunciado de Testo yonqui imagina la propia potencia del texto en un gesto de presentación crítica. Para avanzar en ese sentido, conviene empezar brevemente con unas reflexiones sobre uno de sus libros más recientes: $U n$ apartamento en Urano (2019), prestando particular atención a su subtítulo: «Crónicas del cruce». Se trata de una recopilación de textos, columnas de opinión — pero también algunos ejemplos de piezas plenamente literarias, como, por ejemplo, «Ne(Cr)oliberalismo»—, escritos para el periódico francés Libération y para algunos otros 
medios europeos entre 2010 y principios de 2018. Sobre el desarrollo de esta obra, Preciado señala lo siguiente:

Cuando empecé a escribir estas crónicas mi nombre era aún Beatriz y, aunque disidente desde mi lesbianismo queer, ocupaba una posición social y legal femenina. Acabo este libro, aún en el cruce, firmando con un nuevo nombre y con un documento de identidad que indica que mi sexo legal es masculino $(2019$, p. 28).

El «cruce» no sólo será la clave de la transición de sexo y género, sino también de otro proceso que Preciado coloca como fundamental para entender la transición política global del presente: la migración. Ambas estructuradas como una validación condicionada frente a los «ojos» del Estado, implican también la puesta en cuestión de una arquitectura política y legal del capitalismo colonialista y patriarcal. Estas crónicas, escritas en su mayoría en aeropuertos y hoteles, pero también en aquellos singulares «no-lugares», ambos procesos de cruce se intersectan en las escenas prototípicas del libro, cuando Preciado es interpelado por la autoridad para cruzar fronteras cuando su estatuto legal-sexual en ese momento no estaba resuelto: «Con una apariencia cada vez más masculina y un documento de identidad femenino, perdí el privilegio de la invisibilidad social y de la impunidad de género» (Preciado, 2019, p. 33). A cada paso, su pasaporte, como índice de movilidad reglamentada, era cuestionado por no adaptarse a la normativa escópica del poder.

Este desvío por Un apartamento en Urano es significativo como puerta de entrada a nuestra lectura de Testo yonqui, en particular porque nos permite ubicarlo, aunque problemáticamente, en la genericidad propia de la crónica. Ante esto, Preciado es un autor particularmente preocupado por el estatuto y la inscripción genérica de sus libros. En este sentido, la introducción de Testo yonqui se pregunta explícitamente sobre estas cuestiones y ensaya una respuesta rica en potenciales de análisis. Allí, Preciado señala:

Este libro no es una autoficción. Se trata de un protocolo de intoxicación voluntaria a base de testosterona sintética que concierne al cuerpo y los afectos de B. P. Es un ensayo corporal. Una ficción, es cierto. En todo caso y si fuera necesario llevar las cosas al extremo, una ficción autopolítica o una autoteoría (2014, p. 15).

La dificultad de caracterizar el propio proyecto, proveniente quizá de una concepción implícita del género textual como «encasillamiento», se lee de forma muy evidente en los vaivenes alrededor de la atribución ficcional del texto, que no deberíamos entender en términos puramente literarios, sino más bien filosóficos, específicamente nietzscheanos. Ahora bien, lo que sí queda claro es que se trata de un proyecto híbrido donde ese «cruce» vuelve a cobrar relevancia. Podremos afirmar esto —el carácter híbrido del texto de Preciado-, sólo a título de no implicar una pureza genérica previa que en un momento lógica y cronológicamente posterior se pondría en «contaminación». Más bien, lo que habría que conservar conceptualmente es que este tipo de operaciones nos conminan, con palabras del xenofeminismo - interlocutor clave de Preciado en sus trabajos posteriores- , a pensar en la hibridez «sin la infección de la pureza» (Hester, 2019, p. 13). Preciado señala que ser transexual es «aceptar que uno solo es uno mismo gracias y a través del cambio, del mestizaje, de la mezcla» (Preciado, 2019, 


\section{Moléculas y postporno en Testo yonqui. Una lectura literaria de Paul B. Preciado}

p. 31). En este sentido, podríamos señalar — si se nos permite el pobre juego de palabras—, que Testo yonqui se apoya, no solo temática, sino también genéricamente, en una «estética trans», basada en estos procesos de cruce, mezcla, mestizaje e hibridez.

Ahora bien, nuestra operación de leer Testo yonqui como un ensayo-crónica no se apoya solamente en el traslado del subtítulo de Un apartamento en Urano al texto en cuestión, aunque verdaderamente arroje alguna luz sobre el asunto. Podríamos, más bien, sumar dos operaciones críticas más fuertes. En primer lugar, un argumento de matización de los límites genéricos. Junto con Alicia Montes (2013), diremos que, partiendo del reconocimiento de elementos narrativos fuertes no-ficcionales en el texto de Preciado, no hay una distinción neta y apriorística entre la autobiografía y la crónica. ${ }^{1}$ Más bien, se trata de reconstruir a posteriori qué tipo de genericidad resulta productiva para leer al texto eficazmente, más allá de esa «contaminación» ineludible. Y, en este sentido, debemos reconocer que la estrategia autofigurativa, por un lado, no se apoya en el gran arco de los materiales de una vida, sino más bien en unos eventos puntuales y claramente delimitables y, por otro, el problema fundamental del texto es la relación entre un yo y un(os) otro(s), problema estructurante de la crónica hispanoamericana, desde «las crónicas de indias» (Todorov, 2007). Al respecto, Preciado declara lo siguiente: «No me interesan aquí mis sentimientos, en tanto que míos, perteneciéndome a mí y a nadie más que a mí. No me interesa lo que de individual hay en ellos. Sino cómo son atravesados por lo que no es mío» (Preciado, 2014, pp. 15-16) —las cursivas son nuestras - En un mismo gesto, el autor se distancia de un intimismo como «propiedad intransitiva del yo»e instala como interrogante singular la relación con el otro. A renglón seguido, Preciado enumera esas instancias, identificando la historia natural del planeta, la historia económica, la historia técnica, la historia de los dispositivos de poder. Pero una lectura a los procedimientos figurativos del texto ofrece también resultados diferentes. Además de los elementos recién señalados, la problemática se concentra en la figuración de un otro vital —la muerte de su editor y amigo G. D., Guillaume Dustan, al que el texto todo el tiempo refiere en segunda persona-, un otro sexual-amoroso - V. D., la autora y cineasta feminista Virginie Despentes, que ocupa largos tramos de la obray un otro molecular (la testosterona), en los que adhieren el resto de los elementos antes mencionados. En este sentido, en sus aspectos narrativos, Testo yonqui puede entenderse como la elaboración de la pérdida de un ser querido, como el relato de una nueva aventura amorosa y como el experimento hormonal sobre el propio cuerpo. En el final de la introducción, Preciado concluye lo siguiente:

Si el lector encuentra dispuestos aquí, sin solución de continuidad, reflexiones filosóficas, narraciones de sesiones de administración de hormonas y relatos detallados de prácticas sexuales es simplemente porque este es el modo en el que se construye y se deconstruye la subjetividad (Preciado, 2014, p. 16).

Aunque una lectura esquemática del texto ofrece una repartición, en principio, un poco más ordenada —los

1. Uno de los pocos estudios literarios sobre Testo yonqui piensa el texto bajo las coordinadas genéricas de la autobiografía (Conde Arroyo, 2019). Su intuición sobre el carácter híbrido de la obra revistió de particular interés para nuestro trabajo. Conde Arroyo lee la obra de Preciado desde la deconstrucción derrideana, atendiendo a las dificultades y las contradicciones performativas de una ubicación genérica. 


\section{Moléculas y postporno en Testo yonqui. Una lectura literaria de Paul B. Preciado}

capítulos pares serán ensayísticos, los impares narrativos-, lo importante en esta instancia aproximativa es que el montaje característico de la obra, su hibridez sin pureza, tiene como objetivo pergeñar, desde genericidades propias de la cultura letrada, un modo singular de constitución y destitución de la subjetividad en la era digital.

\section{La escritura como tecnología}

El método práctico que comanda tal objetivo será denominado tardíamente en el texto como «principio autocobaya»: «Soy la molécula y el Estado, soy la rata de laboratorio y el sujeto científico que lleva a cabo la investigación» (Preciado, 2014, p. 119). De este principio se deduce que el cuerpo propio, que es también el cuerpo de la multitud - aunque Preciado reconoce una y otra vez su situación privilegiada en el orden geo-etnopolítico-, junto con los entramados de poder que lo constituyen - que ya nos encargaremos de caracterizar prontamente - son, al mismo tiempo, procesos de sujeción y control, como «espacios posibles de agenciamiento crítico y de resistencia a la normalización» (p. 275). Se trata, entonces, de abrir, en el seno de lo personal — que, fiel a su feminismo, es eminentemente político — un laboratorio de experimentación corporal y semiótico-tecnica. Frente a la progresiva externalización de la investigación propiciada por el derrotero de la ciencia occidental, Preciado aboga por un proceso de autoevenenamiento dirigido e intencional, una «intoxicación voluntaria» (p. 276). Si, junto con Foucault y Butler, Preciado reconoce que las distinciones sexogenéricas son procesos culturales, se transforma en un imperativo, como modo de constitución de un sujeto político contemporáneo, el experimentar con esas construcciones. El «principio autocobaya», entonces, es un «modo de producción saber y transformación política» (p. 277) que discute con las formas narrativas dominantes de la filosofía contemporánea. En este sentido, una escritura o una filosofía que no pase por el propio cuerpo es una tarea vacía, una escritura o una filosofía que no se reconozca como «tecnología del yo» inmediatamente cercena o reprime el potencial transgresor de la misma. Es en esta pretensión que el protocolo de autointoxicación adquiere una función clave. Frente a esto, Preciado expone lo siguiente:

Las sustancias químicas asimilables por el organismo operan como potencia: tienen el poder de provocar un cambio sustantivo de estado. Con la condición de que la subjetividad se deje afectar, se haga dinámica, en el sentido griego del término dynamis, es decir, deje emerger su potencialidad, su capacidad de pasar de un estado a otro (2014, p. 282).

Si bien Preciado ubica su experimento narcótico en relación con los de Freud y Benjamin, aunque también podríamos agregar los de Castaneda en Las enseñanzas de Don Juan (1974) o, más recientemente, los de María Moreno en Black Out (2016), la apelación a los griegos puede servir como una oportunidad para ubicar sucintamente sus operaciones en un arco más amplio que nos lleva, con las debidas mediaciones, hasta la Antigüedad occidental, en el marco de una estrategia de reapropiación situada de ciertas prácticas (Cassin, 1994). Aquí es donde los trabajos tardíos de Foucault vuelven a ser útiles para nuestros propósitos. Una de las consignas políticas del filósofo francés señala que la tarea contemporánea no era tanto descubrir la verdad de lo que somos sino buscar 
Moléculas y postporno en Testo yonqui. Una lectura literaria de Paul B. Preciado

un modo de rechazar aquello que somos, consigna con la que Preciado estaría fundamentalmente de acuerdo. Para lograr este objetivo, es necesario hacer una «ontología de nosotros mismos» que revele el carácter histórico, contingente - y por ende mutable — de aquello que nos caracteriza.Por eso,, en sus últimos trabajos, el autor se remonta a la Antigüedad greco-latina para demostrar cómo diversas «tecnologías del yo», entre ellas, la escritura del yo, constituyen el espacio privilegiado de emancipación y sujeción del sujeto. Podríamos definir, pues, a las «tecnologías del yo» como una serie de operaciones sobre el propio cuerpo y alma, pensamientos, conductas o modos de ser, que buscan la autotransformación para obtener cierto estado de felicidad, pureza, sabiduría, perfección o, incluso, un gobierno efectivo sobre los otros (Blanco, 2020).

En ese sentido, Foucault analiza dos fases de aquellas tecnologías, que nos servirán como contrapunto para analizar el proyecto de Preciado. Por un lado, la Antigüedad grecolatina, y por otro, la espiritualidad cristiana y los principios monásticos. La gran diferencia entre estas dos fases está dada en las consecuencias que éstas juegan en la conformación del sujeto. Mientras que en la Antigüedad greco-latina las tecnologías del yo implicaban que la subjetividad era un proceso, una dinámica continua del alma y el cuerpo, en el paradigma cristiano, esas tecnologías implicaban una extrema atención a la contemplación y la obediencia al maestro, donde el deseo se pone bajo la vigilancia como un secreto que debe ser mostrado y castigado (Blanco, 2020). En esta esquemática presentación, focalizando principalmente en la dynamis del material subjetivo y en la mayor atención hacia el cuerpo, se podrá entender que el experimento de Preciado está más cerca de las tecnologías grecolatinas que de las cristianas. Incluso si se comparan las operaciones específicas, por ejemplo, de los estoicos, tales analogías se expanden. En los estoicos, una de las grandes tecnologías del yo es la gymnasia, un tipo de entrenamiento en la vida corporal que puede ser artificialmente inducido. De todos modos, los estoicos tendían más bien a practicar la abstinencia sexual y la privación física, mientras que Preciado se adentra en la exploración sexual y narcótica. El problema es que los objetivos de las dos tecnologías son, en un sentido fuerte, antitéticos: mientras que los estoicos intentaban probar la independencia del individuo frente al mundo exterior, Preciado, como ya señalamos, quiere demostrar los efectos de un amplio abanico de «otros» — no solo otras personas sino, también, moléculas sintéticas - en la constitución de la subjetividad.

Esta aclaración nos permitirá pasar al modo en que una zona de la teoría de Judith Butler nos permite leer la obra de Preciado en tanto tecnología literaria. En varios trabajos, Butler se perfila como una continuadora de los análisis de las tecnologías del yo en sentido foucaulteano, figurando un análisis de las mismas en la modernidad. En The Psychic Life of Power, Butler (1997) reinterpreta los procesos de subjetivación foucaulteanos, en relación con el poder y la resistencia, a través de la presentación de un sujeto que es constituido en su origen como un plegamiento, un retornar a sí mismo. Para Butler, la subjetividad es definida como un proceso en el que la otredad afecta y precede la enunciación del «yo», donde ese origen está reprimido y, por ende, subordina al sujeto. Para la filósofa norteamericana, es precisamente la «narración de sí», la escritura del yo, la que permite superar el impasse del círculo vicioso entre el poder y la subordinación. Pero este «dar cuenta de sí mismo» encuentra un límite inmediatamente, esto es, el sujeto no puede dar cuenta del proceso que lo constituye porque es un plano que 
Moléculas y postporno en Testo yonqui. Una lectura literaria de Paul B. Preciado

lo excede y lo precede. Aun así, las «narraciones del yo» se construyen sobre este nuevo impasse y se emplazan sobre la paradoja de intentar relacionarse con una instancia previa a la emergencia de sus propias capacidades narrativas, y es eso el nacimiento de la narración. Preciado resuelve, pues, esta imposibilidad recurriendo al ensayo, ya que es precisamente el aparato teórico lo que permite dar una luz sobre el modo de constitución del sujeto de la narración, a modo de ilustración descriptiva del dispositivo de poder que el autor rechaza en los actos. De esta manera, fiel a su inscripción a los estudios literarios, nuestra lectura piensa a la teoría del filósofo español como una función de su narrativa y no al revés.

De todos modos, sobrevalorar o sustancializar este esquema puede llevar a una deformación de los procedimientos del texto, pues la relación entre teoría y práctica no es dicotómica ni unidireccional. Más bien, como señalaría Foucault, ni la teoría otorga valor de verdad a la práctica, ni la práctica desacredita una teoría como especulación pura y vacía. Frente a esta dificultad, Preciado utiliza la práctica experimental, literaria y política como un intensificador de la teoría, lo cual hace que los análisis categoriales funcionen como un multiplicador de las formas y los ámbitos de intervención del lenguaje y los cuerpos (Foucault, 2018 [1983]). De este modo, en Testo yonqui, el carácter técnico del lenguaje se pone de manifiesto y la literatura se constituye como una fuerza, como «ingeniería vital», como «donación de forma» (Mosquera, 2020).

\section{Las matrices de la ciencia ficción entre la paranoia y el poder}

De alguna manera, probablemente este sea el momento para remarcar brevemente, en el plano teórico, las distancias que Preciado impone en dos de sus autores de referencia intertextual más importantes: Michel Foucault y Judith Butler. Por una parte, del filósofo francés, Preciado retoma la noción de la sexualidad como parte de un dispositivo de poder, reconociendo también el carácter eminentemente productivo (y no represivo) de éste. El poder será, como un Foucault, eminentemente «biopolítico», por ser la vida el objeto de sus cálculos y estrategias. Pero, en lo que será razonablemente un lugar común de los estudios posfoucaulteanos, Preciado enfatiza que los análisis sobre el carácter individualizante de la «anatomopolítica» y los totalizantes de la «biopolítica» son, en lo fundamental, muy insuficientes para pensar la contemporaneidad. Particularmente, el texto analizado en el presente artículo estaría definido más bien por un nuevo régimen de poder que el autor llama «sociedad farmacopornográfica», entendido como un dispositivo marcado por el uso de las nuevas tecnologías en el cuerpo (biotecnologías, cirugía, endocrinología, drogas sintéticas, etc.) y en la representación sexual (fotografía, cine, televisión, cibernética, etc.). Lo determinante de estas nuevas tecnologías es que, lejos de la ortopedia exterior del poder disciplinario, se trata de estrategias «ergonómicas» del poder, que se infiltran y penetran en la inmanencia de la vida, incorporándose en el cuerpo de múltiples maneras, constituyendo así una «microprostética», una «miniaturización, internalización e introversión» (Preciado, 2014, p. 72) de los dispositivos de vigilancia y de control que construyen el dispositivo sexo-genérico, dispositivos que toman la forma del cuerpo que controlan, con el objetivo de «devenir subjetividad» (p. 73). Frente a este marco, en el capítulo «Devenir T», el filósofo 


\section{Moléculas y postporno en Testo yonqui. Una lectura literaria de Paul B. Preciado}

español apunta: «Cuando me administro una dosis de gel de testosterona o me inyecto una dosis líquida, me estoy suministrando en realidad una cadena de significantes políticos que se materializa hasta adquirir la forma de una molécula asimilable por mi cuerpo» (p. 118). Respecto de Butler, el autor reconoce la importancia de identificar el dispositivo de género como una serie de aparatos performativos que construyen culturalmente a partir de rituales y repeticiones aquello que luego se esencializa y naturaliza como diferencia sexual. Pero el teórico no se cansa de recalcar que el límite de tal teoría es su carácter eminentemente discursivista, apuntando que es también el cuerpo, el sexo y la materialidad lo que es tecnológicamente producido e intervenido a través de los dispositivos de poder. Así, aclara, siempre alrededor de lo que se deduce de su propia experiencia narcótica, lo siguiente:

El consumo de testosterona, como el consumo de estrógeno o de progesterona en el caso de la píldora, no depende de no se sabe qué construcciones culturales de género que vendrán a influir en el modo en el que actuamos o pensamos. No. Nos confrontamos aquí directamente a la producción de la materialidad del género (Preciado, 2014, p. 121).

De este modo, Preciado discute con Foucault expandiéndolo a través de las «sociedades de control» deleuzianas e incluso - aunque con reservas - el obrerismo italiano, y, con Butler, contraponiéndole el tecno-materialismo sexo-genérico de los trabajos de Donna Haraway e, incluso - aunque se trata de publicaciones posteriores-, el xenofeminismo.

Esta última apelación reviste de tal importancia para nuestra lectura en clave literaria que merece un examen atento. De Donna Haraway (1984), Preciado retoma tanto su tecno-materialismo como su hipótesis fundamental sobre el carácter prostético (o técnico) del dispositivo de género. Para ello, Haraway toma una decisión que impacta también en la textualidad de Preciado y que la ubica en el centro de nuestro objeto de estudio, es decir, el rastreo de las transformaciones de la literatura en la era digital: la apelación a las matrices de la historia de la ciencia ficción. Quizá este tipo de consulta no resulte tan extraña si consideramos que la ciencia ficción — desde sus orígenes con Frankenstein de Mary Shelley pero con mucha más fuerza en la obra de Ursula K. Le Guininterpeló problemáticas afines al feminismo y ubicó la experimentación con las categorías de género en el centro de sus preocupaciones. Haraway aprovecha, de ese modo, el núcleo de significación de la ciencia ficción, que piensa las interrelaciones íntimas entre lo técnico y el cuerpo, planteando que la categoría de cyborg (contracto de cybernetic organism) nos permite elaborar un pensamiento que supere la dicotomía entre naturaleza y cultura y, por lo tanto, llegar a una formulación sobre el carácter - técnicamente - construido del género y el sexo.

Preciado, por su lado, aunque supone y extiende la intertextualidad propia de Haraway, utiliza unas matrices específicas, aquellas del subgénero del cyberpunk. Este tipo de retraducción impacta de diversas maneras en varias zonas de su textualidad, pero en los niveles más pregnantes influyen en la utilización del lenguaje los modos de tramar los argumentos y en la referencia a una episteme singular. Respecto al primer punto, la textualidad del teórico español, tanto en las partes ensayísticas como las más propiamente de crónicas, deja leer lo que puede caracterizarse, a la manera en que De Rosso (2012) caracteriza al cyberpunk, como un uso pirotécnico del lenguaje. Se trata de una pragmática inflamatoria del discurso, que tiene su raíz también en otra matriz subyacente al texto: la del manifiesto, que impregna una y otra vez el libro y que busca estallar, con un método calculado, en la cara del 


\section{Moléculas y postporno en Testo yonqui. Una lectura literaria de Paul B. Preciado}

lector. Aunque este tipo de operación se puede rastrear de diversos modos, probablemente no haya evidencia más cabal de ella que en la formación continua, central también al cyberpunk, de neologismos: «videopenetración» (Preciado, 2014, p. 20), «farmacopornografía» (p. 35), «tecnoproducción» (p. 43), «tecnogénero» (p. 89), «tecnoseno» (p. 152), «testogirl» (p. 119) — cursivas del original—, «pop-control» (p. 138), «cyber-paraiso» (p. 197), entre muchos otros casos. Lo que se pone en juego en este punto es tanto la capacidad de sintetizar un concepto en una palabra como la caracterización más general del fenómeno estético: la compatibilización de heterogéneos, con su respectivo extrañamiento, que encuentra una declinación singular en Preciado como búsqueda de «excitación», que ya nos encargaremos de caracterizar.

La estructura narrativa básica del cyberpunk consiste en la elaboración de lo que podría llamarse una «hipótesis paranoica». En este subgénero de la ciencia ficción, se ha abdicado de la figura del Estado, porque el verdadero poder se encuentra en las redes informáticas, plataforma de las empresas multinacionales que se constituyen como un foco de poder omnímodo y hacen de los personajes meros peones de fuerzas que los superan y que nunca entienden del todo. En palabras de De Rosso, lo que triunfa en el cyberpunk es la idea de un «orden global como conspiración» (2012, p. 320). En la obra de Preciado, por su parte, aunque no se deseche la importancia de los aparatos del Estado, se observa tanto la importancia de las redes informáticas como la de la figuración del sujeto individual, en todos sus niveles, pero específicamente en el nivel de la sexualidad y el género, como objeto de disputas políticas de redes de poder que lo superan infinitamente. Frente a esta evidencia del carácter, al menos superficialmente, inerme de los sujetos, Preciado elabora un programa político caro a la matriz genérica del cyberpunk: la necesidad de constituirse como «hackers de género». En una de sus caracterizaciones del dispositivo sexo-genérico, define lo siguiente: «El género funciona como un programa operativo a través del cual se producen percepciones sensoriales que toman la forma de afectos, deseos, acciones, creencias, identidades» (Preciado, 2014, p. 98). Frente a tal normalización, el teórico español propone humorosamente una serie de ejercicios de «reprogramación de género», desde la «gestión de la dependencia económica» al «devenir un macho de élite» o un «rey de la sodomía» (pp. 300-304). Los y las gender hackers no son simplemente las personas que intervienen técnicamente sobre su programación de género, sino las personas que lo ejercen en una posición de excentricidad respecto de las redes de poder. En el ejemplo que brinda el filósofo, serían las personas transexuales que, en el marco de una terapia hormonal, no se someten al aparato médico que las patologiza y las caracteriza como «disfóricos de género», sino más bien las que acuden al mercado negro para escapar de las clasificaciones del poder. En este sentido, como en el cyberpunk, estos hackers se hacen de las herramientas hegemónicas para darles un uso no capitalista ni patriarcal ni hegemónico. La analogía, entonces, está completa:

Los hackers informáticos utilizan Internet y los programas copyleft como herramientas de distribución libre y horizontal de información, y afirman con acierto que el movimiento social que ellos lideran está al alcance de todo el mundo vía Internet. El movimiento farmacopornográfico copyleft tiene una plataforma tecno-viva mucho más fácilmente accesible aún que Internet: el cuerpo. Pero no el cuerpo desnudo, el cuerpo como naturaleza inmutable, sino el cuerpo tecno-vivo como archivo biopolítico y prótesis cultural (Preciado, 2014, p. 316) —las cursivas son del original-. 
Contra el marco intensamente regulado y capitalizado de las hormonas — entre el aparato médico y las empresas farmacéuticas - , los y las «hackers de género» inauguran una sexualidad de lo común. Pero para entender más cabalmente el funcionamiento de la hipótesis paranoica en Preciado debemos distanciarnos momentáneamente del cyberpunk para entenderlo desde el trabajo de una de las críticas literarias queer más importantes del siglo xx, referenciada en los agradecimientos de Testo yonqui: Eve Segdwick. En un texto seminal sobre la problemática, Segdwick (1997) manifiesta cierta inconformidad con que el modo paranoico de tramar argumentos se ha hecho equivaler, en la modernidad, al propio ejercicio de la crítica, en su sentido amplio. Herederos y herederas de los principios de las «hermenéuticas de la sospecha» (Marx, Niezstche, Freud), deberíamos, según el objeto de Segdwick, dar un paso más en la autorreflexión y desnaturalizar los axiomas que posibilitan a la hipótesis paranoica. A partir de este punto, resulta necesaria una precisión muy importante: no se está discutiendo nunca el «valor de verdad» de las teorías paranoicas — ni en Preciado, ni en ningún otro texto_-, sino más bien el monopolio de estas formas de pensamiento, cuando un análisis atento a nuestras prácticas revela una multiplicidad de maneras de leer y hacer crítica que no son inmediatamente paranoicas. Para ello, debemos caracterizar con soltura las características más pregnantes de este tipo de teorías. Según la feminista estadounidense, las teorías paranoicas son anticipatorias - con una vigilancia orientada al futuro que busca evitar las sorpresas indeseadas-, reflexivas y no ingenuamente miméticas - basadas en un tropismo en el que ocupan a la vez la posición de un modo de conocer y de la cosa conocida_- teorías fuertes — en el sentido del alcance y una suerte de reduccionismo latente-, basadas en afectos negativos — con el objetivo de minimizar la humillación, la opresión — y en una fe axiomática en el valor político inmediato de la exposición de las asimetrías sociales. En este sentido, no resulta demasiado dificultoso identificar tales características en la obra de Preciado. Por eso, Testo yonqui es anticipatoria, ya que estudia la historia del dispositivo sexo-genérico para diagnosticar el presente y prefigurar el futuro; es también reflexiva, pues continuamente se generan preguntas por sus propias condiciones de enunciación, especialmente, por las consideraciones sobre la posición privilegiada de Preciado en el sistema social ; es igualmente una teoría fuerte, pues pretende que su modo de leer las transformaciones del dispositivo en cuestión caracterizan inmediatamente la totalidad del capitalismo tardío, cuyo centro son los afectos negativos — principalmente, se busca evitar la normalización del dispositivo en cuestión - y una confianza no evidente en la capacidad de influencia política de la propia teoría. Ahora bien, resulta de vital importancia entender que no se puede reducir a Testo yonqui como una forma sin más de la paranoia, dado que el texto encuentra un balance con, precisamente, las zonas más literarias, con un carácter muy cercano a la crónica. Ahondaremos sobre este punto hacia el final del artículo.

El último punto en que la referencia a las matrices del cyberpunk resulta productivo para leer a Preciado se relaciona con el modo en que el texto apunta a una mutación epistémica en ciernes como condición interpretativa. En este sentido, comparte con aquel subgénero de la ciencia ficción la grilla de inteligibilidad, el mismo sistema de saber, la misma reorganización de los discursos y los conocimientos: la episteme de la información. La 
Moléculas y postporno en Testo yonqui. Una lectura literaria de Paul B. Preciado

proliferación de sistemas informáticos y la progresiva intimidad entre lo vivo y lo técnico son motivos recurrentes, estructurantes y productivos del cyberpunk, pero también, en parte, de Testo yonqui. No podremos profundizar en la caracterización — de por sí compleja — de esta nueva episteme, pero valga, para los efectos de este trabajo, señalar su aspecto fundamental: el descubrimiento de la noción de información. En un camino que va desde la ingeniería de la telecomunicación a la genética, pasando también por la matemática, la física, la lingüística, la psicología y la sociología, la postulación de la información, como diferente pero no disociada de las categorías de materia y energía, introduce una reorganización sin precedentes de los saberes.

Tal como lo señala Pablo Rodríguez (2019), al lidiarcon el problema de los mensajes encriptados en la Segunda Guerra Mundial, ingenieros de telecomunicaciones — salientemente Claude Shannon, de los laboratorios Bell, de la compañía telefónica AT\&T - elaboran un corte con la criptología tradicional, que analizaban los códigos y las señales a partir de la selección de símbolos con la misma probabilidad de aparición. Según Shannon (1948), para descifrar un mensaje cuyo código no se conoce, se requiere precisar la identificación de ciertos patrones de aparición de los símbolos. Su conclusión fue que debía aplicarse el cálculo de probabilidades a la medición de aquello que sus compañeros de laboratorio habían llamado «información»: según la teoría matemática de la información, la cantidad de información se define como la suma del logaritmo de las probabilidades de aparición de los diferentes símbolos. Y esta postulación, con sus respectivas reelaboraciones a lo largo de las décadas, por ejemplo, clásicamente, el recentramiento del receptor en lugar del emisor como el foco de análisis de la información, se reveló efectiva no solo para teorizar y practicar los mensajes encriptados y las telecomunicaciones, sino, muy pronto, para un abanico enorme de fenómenos que encontraba ahora una nueva inteligiblidad: el ADN y la inmunología en la biología, la reelaboración del hecho de la comunicación, la construcción de máquinas cibernéticas y un largo etc. La consecuencia epistémica fundamental de este proceso histórico fue que aquellos rasgos que se consideraban específicamente humanos — relacionados en particular con el lenguaje: el código, el mensaje, el sistema, la organización, la formalización, el cálculo- comenzaron a ser proyectados y repartidos en una multitud de seres, entre lo viviente en general y lo técnico (Rodríguez, 2019). Ante este descubrimiento, ninguna disciplina de conocimiento quedó inmune a su influjo, pues desde ese momento ya todo empezaría a comunicarse, a expresarse, a codificarse.

Y es precisamente de esta fuerza del pensamiento de la que Preciado se hace cargo y la transforma en una cifra singular de su productividad textual, ya que los ejemplos más o menos desconectados abundan en el texto, y tal decisión permea la estructura de las hipótesis del ensayo. Cabe recordar que la postulación principal de Testo yonqui apunta a que en la contemporaneidad el dispositivo sexo-genérico se constituye como un régimen farmacopornográfico. Respecto del primer aspecto de tal atribución, el farmacopoder se constituye inmediatamente como cibernética,es decir, como ciencia del control, basado en los principios informáticos; así, se entiende al experimento Brown-Sequard como la «primera teoría de la transmisión de información a distancia en la que las secreciones se entienden por primera vez como "mensajes químicos"» (Preciado, 2014, p. 132). Por ende, la constitución, de la episteme de la información a lo largo del siglo xx deberá entenderse como un 
contexto dominado por la comunicación, el viaje, el intercambio, la conexión y la influencia [...] [en el que aparece] un interés creciente por la circulación de fluidos y la transmisión de la información dentro del cuerpo que acabará dando lugar a la invención de la hormona como secreción comunicante (Preciado, 2014, p. 130).

En este sentido, las terapias hormonales se constituyen como una acción a distancia molecular que afecta otras acciones, es decir, como dispositivo de poder. En esta grilla de inteligibilidad, el cuerpo no es simplemente un dato natural, sino más bien el efecto material de unos intercambios semiótico-técnicos. Por supuesto, el caso de las terapias hormonales para la reasignación de sexo son el caso más evidente del carácter cibernéticamente construido del sexo y el género, pero tal caracterización es productiva para otras zonas del farmacopoder: desde las píldoras anticonceptivas — que Preciado cataloga como un «panóptico comestible»_ hasta las terapias psiquiátricas y las drogas recreativas. Todos estos ejemplos dan cuenta de la molecularización del poder que constituye técnicamente la subjetividad en diversos niveles.

Respecto de la pornografía, la inteligibilidad cibernética resulta un tanto más evidente. Por supuesto, la pornografía existía antes de internet, pero fue solo con el establecimiento de grandes redes informáticas que se transformó en un fenómeno ubicuo y se cristalizó como aparato sexo-genérico general. La pornografía es, pues, sexualidad transformada en espectáculo, pero ahora será también un dispositivo virtual, información digital, representación pública y comercializable a gran escala. Al respecto Preciado considera lo siguiente:

La pornografía es teletecnomasturbación. La globalización de la farmacopornoeconomía a través de la digitalización audiovisual y su transmisión ultrarrápida sobre una multitud de soportes técnicos (televisión, ordenador, teléfono, iPod, etc.) genera un «efecto mariposa» en la gestión global de los ciclos excitación-frustración: un coño que se abre aquí, una boca que chupa allí, puede producir cientos de descargas de placer al otro lado del planeta y emitir con su desplazamiento virtual un chorro vivo de capital (Preciado, 2014, p. 202).

Como dice el sentido común de la cibercultura, en internet lo que más hay es porno y gatos. Por eso, Preciado aprovecha esta centralidad para imaginar y proponer una reescritura radical del diagnóstico sobre las sociedades posfordistas. El trabajo en el capitalismo tardío extrae su paradigma de su propia periferia, de lo que considera como marginal: las drogas, el porno y el trabajo sexual. En estos tres ámbitos se intersectan la producción de capital con la producción de subjetividad como prótesis técnico-somática, auténticos tours de force para poner la potentia gaudendi (la potencia de excitación, la potencia deseante) a trabajar: «[El trabajo] más que inmaterial debería calificarse de über-material, supra-material, tecno-material o hiper-material, puesto que su consistencia es biológica, molecular, al mismo tiempo carnal y numérica, irreductiblemente sináptica y digitalizable» (p. 222). En última instancia, en el régimen farmacopornográfico, el texto, la imagen, la técnica y la corporalidad fluyen en el circuito cibernético, determinando cada uno de los niveles de la sociedad. 


\section{El movimiento reparativo}

Aquí, emplazada una serie de líneas compositivas y núcleos problemáticos del texto, llegamos al punto fundamental de nuestra lectura. En un sentido general, afirmaremos que la zona de crónica del texto se constituye como contrapunto estratégico del régimen farmacopornográfico y su modo paranoico de describirlo. Comencemos por la manera de tramar los argumentos. Habíamos señalado que la hipótesis de Preciado es una teoría anticipativa, reflexiva, basada en evitar afectos negativos; una teoría fuerte con una confianza no probada en el valor político de la exposición retórica. Ahora bien, cuando se torna literaria, la textualidad del feminista español tiende a balancear esas tendencias y a suspender algunas de sus determinaciones, en un gesto que, de la mano de Segdwick (1997), definiríamos como «reparativo». Una lectura reparativa es aquella que se abre a la posibilidad de la sorpresa del encuentro con afectos positivos, haciendo hincapié más bien en el presente que en el futuro, dejándose llevar por el placer corporal y cognitivo de un proceso. La forma prototípica de lo reparativo, para la teórica estadounidense es, precisamente, el amor. En Testo yonqui se presenta el encuentro con aquel otro, que es V. D., como una instancia de irradiación de goce, de felicidad y de experimentación con el propio cuerpo y el de su amante. En términos generales, las páginas dedicadas al relato amoroso constituyen la detención y la mitigación del impulso conceptualizador, tendiendo más bien a una escritura eminentemente perceptiva y deseante. Si los conceptos vuelven, volverán en forma inmediatamente performática o decididamente humorística, como un juego, que suspende la seriedad del mundo, que crea un mundo dentro del mundo, con reglas específicas. Muy significativa es la ocasión en la que Preciado se dispone describir a su amante en términos explícitamente leibnizianos: «La más perfecta de todas las realidades y la que ocupa menos volumen, es decir, la que menos molesta, es su amor» (p. 249).

Pero en este punto es donde el modo de tramar reparativo de los argumentos implica inmediatamente también un modo de contestación al régimen farcopornográfico. Apelando a ambas zonas del compuesto conceptual, tanto al farmacopoder como al pornopoder, la respuesta de Preciado será la de la experimentación, la experimentación sexual pospornográfica y la experimentación hormonal no hegemónica, un tipo de actividad que, hacia el final del artículo, caracterizaremos como «promoteísmo sexogenérico». Largas páginas del libro están dedicadas a relatar los encuentros sexuales con su amante. Así, a modo de ejemplo paradigmático:

Los cuerpos giran juntos, las pelvis se acercan magnéticamente, los sexos al mismo tiempo unidos y separados por el tejido del pantalón, después soy yo el que me follo su boca con la lengua. Una y otra vez hasta que la saliva cae en chorros sobre su cuerpo (Preciado, 2014, p. 81).

La clave de este tipo de fragmentos es, precisamente, la pospornografía, cuyo objetivo no es meramente masturbatorio, sino político, crítico o humorístico. Como define en otra zona del texto: «Se trata [...] de inventar otras formas públicas, compartidas, colectivas y copyleft de sexualidad que superen el estrecho marco de la representación pornográfica dominante y el consumo sexual normalizado» (Preciado, 2014, p. 206) — las cursivas 
Moléculas y postporno en Testo yonqui. Una lectura literaria de Paul B. Preciado

son del original - . Ahora bien, leído bajo los parámetros antes delineados, el posporno se encuentra en un lugar ambiguo que pivotea continuamente entre un momento paranoico y otro momento reparativo. Por un lado, un impulso implícito de este tipo de práctica conlleva la desnaturalización de la imagen pornográfica, la revelación de su carácter construido, contingente y cómplice del régimen patriarcal. Pero, por otro, aún más fundamental, se trata de experimentar con otras formas de la imagen de la sexualidad, formas que se liberen precisamente de esa estrechez de miras que impone el régimen del pornopoder. En última instancia, la práctica pospornográfica, entre lo paranoico y lo reparativo, tiene un momento negativo, destructivo, y un momento positivo, propositivo ${ }^{2}$. En las vísperas de una relación sexual con V. D., Preciado deja volar su fantasía y su imaginación, un tipo de variación que no es estéril, sino que apunta al centro de su argumentación: «Me imagino sin polla y con polla alternativamente, los dos cuerpos se suceden como en un juego de balancín» (Preciado, 2014, p. 80). El problema, como inmediatamente lo hace saber el texto, es que tal ensayo con las posiciones sexogenéricas no implica que un retorno de los habitus de los dispositivos de poder, específicamente aquel que se organizaba alrededor de la visión —el régimen escópico de la genderización —, no pueda poner en peligro toda la intentona: «Pero sé que cuando me desnude ella solamente verá uno de esos cuerpos. Esa reducción de mi cuerpo a imagen fija me asusta» (p. 80). De este modo, en el «balancín», no sólo está la autopercepción de su cuerpo, sino también la efectividad del régimen fijista de género que se busca derribar.

La otra vertiente de la experimentación, que se intersecta fuertemente con la primera, es la del consumo de la testosterona: la «T». Preciado, en este momento, a diferencia de su derrotero años después, como se evidencia en Un apartamento en Urano, se resiste a hacer una transición médico-legal de cambio de sexo y género, e interpreta, con buenas razones, que tal decisión constituye una asestada, al menos en términos paradigmáticos, al régimen farmacopórnográfico. La configuración del autor se piensa como la de gender hacker, un sujeto que hace usos impropios, incluso ilegales, de las herramientas del sistema de opresión, en este caso, las hormonas. La testosterona es, pues, un híbrido semiológico-material:

Lo que me administro no es simplemente la hormona, la molécula; es el concepto de hormona: una serie de signos, de textos, de discursos, el proceso a través del cual la hormona llegó a sintetizarse, la secuencia técnica a través de la cual llegó a materializarse en el laboratorio (Preciado, 2014, p. 118).

Si la hormona es, a la vez, un segmento material y un significante político, el uso hacker de la misma constituye una forma de infectar intencionalmente las bases materiales de la diferencia sexual. La textualidad, cuando pasa a relatar los efectos de la autoadministración, registra desde transformaciones corporales a afectivas: pérdidas

2. Al respecto, Francisco Gelman Constantín (2019) rastrea en la obra del escritor y ensayista uruguayo Ercole Lissardi una relación analógica a la que señala el filósofo español entre medicina y pornografía como grandes mecanismos proveedores de representaciones de un cuerpo desubjetivado que se transforma en pura visibilidad y objeto de intervención. Pero, si el posporno en Preciado aparece como una fuerza de producción alternativa de imágenes de la sexualidad, el erotismo en Lissardi corresponde más bien al desmoronamiento batailleano, que hace colapsar el horizonte de lo humano y suspende el proyecto civilizatorio de la autonomización ilustrada. Ahora bien, según nuestra argumentación, las imágenes y los conceptos que implican al postporno en Preciado suponen, al enmarcarse en un proyecto escriturario que insiste en los modos «cibernéticos» en que la alteridad atraviesa la subjetividad, una puesta en cuestión del proyecto civilizatorio de la identidad autosuficiente de la modernidad. 


\section{Moléculas y postporno en Testo yonqui. Una lectura literaria de Paul B. Preciado}

de sangre, excitación sexual, cambios en la resistencia al cansancio, entre otras. La hormona es, a la vez, una tecnología del cuerpo y una tecnología del alma, francamente interseccional. Esto es explicado por Preciado con las siguientes palabras:

Una de las primeras manifestaciones de la testosterona reside en el sentimiento de que el interior de mi cuerpo es una masa fibrosa y flexible que se puede desplegar en cualquier dirección del espacio; se trata de una certeza orgánica, el sentimiento de que cualquier objeto puede ser inmediatamente atrapado con una intencionalidad muscular, la seguridad de que cualquier obstáculo puede ser sobrepasado (Preciado, 2014, p. 343).

Se trata, como él mismo lo indica, de una sensación de high, de efecto de droga recreativa. Pero no se trata, naturalmente, de efectos puramente positivos. El texto se encarga de señalar de forma repetida que una de las consecuencias indeseadas de la administración es un cambio en los olores corporales que lo persigue, le molesta, lo incomoda. Una y otra vez el peligro del cáncer y de la calvicie surge en la superficie textual, pues ya no se trata de un proceso unidireccionalmente positivo. Progresivamente, los inconvenientes de la autoadministración se revelan como más problemáticos de lo esperado. El consumo se transforma, primero, en posibilidad de adicción, y luego en su realización. Preciado no duda comparar a la testosterona con el dinero, pero también, exagerando un poco el gesto, con la heroína, aludiendo también a su carácter políticamente oneroso: exclusión, marginalización y desocialización. El problema de la testosterona es que inserta al sujeto en un double bind: o se somete al aparato médico-legal y acepta ser patologizado, o se evita el sometimiento al dispositivo y se arriesga a ser considerado como un adicto. En esa circunstancia, no hay una salida fácil.

Una de las imágenes más interesantes es cuando Preciado empieza a tejer lazos entre la adicción a la testosterona y su amor por su amante: «Resulta evidente que mi relación con V. pertenece al tipo de relaciones que se modelan bajo la forma de la adicción» (Preciado, 2014, p. 189). Luego, se preguntará cómo está seguro que pertenece a esa modelización y no a lo que llama como «cibernética de la satisfacción» (p. 189). La respuesta a esa cuestión la encuentra en la relación disimétrica entre ingestión o presencia del objeto deseado y la satisfacción. Luego, la relación con V.D. toma la forma de una falta insalvable: «Cuando la estoy besando pienso en que quiero besarla, cuando hablo con ella pienso en que necesito urgentemente hablar con ella» (p. 189). Así, el deseo nunca alcanza la saciedad, se vuelve un deseo de seguir deseando, un deseo infinito sin posibilidad de colmarse o sosegarse. $Y$ en este punto es donde el filósofo español identifica una reinscripción inusitada dentro de las redes de poder: «El cuerpo adicto y sexual, el sexo y todos sus derivados semiótico-técnicos son hoy el principal recurso del capitalismo posfordista» (Preciado, 2014, p. 39). De este modo, todo el proceso de contestación y reparación respecto del régimen farmocopornográfico se sumerge en una ambigüedad que constituye la fuerza estructurante del texto. 


\section{A modo de conclusión}

Autoficción, ficción autopolítica, crónica autobiográfica, ensayo corporal. El narrador de Testo yonqui es una figura textual preocupada por la participación genérica problemática del texto. Si un modo de leer contemporáneo, que se remonta a ciertos gestos del romanticismo alemán, anuncia el completo divorcio entre la práctica de la escritura moderna en tanto literatura y la vigencia del género como categoría normativa (Blanchot, 1992), la obra de Preciado, leída desde los estudios literarios, demostraría la necesidad de matizar fuertemente tal hipótesis y afirmar la fertilidad del pensamiento genérico. Para Jean-Marie Schaeffer (2001), la idea contemporánea del «estallido del género» supone un relato implícito en el cual el estadio histórico-literario anterior estaría marcado por la estabilidad y la homogeneidad, contra el cual se levantaría esta concepción de lo nuevo como estallido, subversión, crisis, heterogeneidad, indeterminación, disolución y polifonía. Aunque reconoce que en la literatura se produjo una aceleración en los ritmos de transformación genérica a lo largo de los siglos, una tarea de los estudios literarios correspondería a la desnaturalización de una relación única entre el pasado y el presente de las prácticas literarias. Así, esta perspectiva de Schaeffer permitiría demostrar que los textos contemporáneos más ricos se califican, no por una ausencia de rasgos genéricos, sino, al contrario, por su extrema multiplicidad. Es en esta dirección que se pretendió trabajar con la obra del filósofo español. Al señalar, en Testo yonqui, la pertinencia de la genericidad de la crónica en la preocupación por la alteridad — una alteridad posthumana, que se extendía a la testosterona como un «otro» que se introyecta-; al remarcar el recurso de la utilización de las matrices del cyberpunk como modo de pergeñar un relato sintonizado con las relaciones de poder y saber en el capitalismo informacional; al subrayar su concepción de la escritura como una «tecnología del yo» que se podría remontar a la Antigüedad griega, se buscaba eso: pluralizar las coordenadas genéricas de su lectura, enfatizar su hibridez, visibilizar los procesos de mezcla.

En resumen, para finalizar, los niveles formales, materiales, temáticos y pragmáticos del texto se podrían caracterizar como una forma singular de «prometeísmo». Se trata de un concepto formulado al interior de los debates del aceleracionismo, corriente teórica heterogénea que se encargó de repensar los modos de la agencia filosófica, política y cultural dados por la revolución digital. El prometeísmo es una forma de «hacer con lo dado», es una defensa del estatus normativo de la afirmación de que las cosas no son como deben ser, y de que las cosas deberían ser entendidas y reorganizadas. En palabras del filósofo Ray Brassier: «El prometeísmo es simplemente la reivindicación de que no hay razón alguna para asumir un límite predeterminado a lo que podemos alcanzar o a los modos en los que podemos transformarnos a nosotros mismos y transformar nuestro mundo» (2017, p. 203). Esta definición puede servir contingentemente como modo de caracterización de las operaciones de Preciado: a lo largo de las páginas, se comprueba que las experimentaciones a las que se somete no tienen ni principio trascendente, ni limitación exterior, ni camino prefijado. El género —en su vertiente sexual y literaria—, el amor, las drogas y la subjetividad en su conjunto entran en un proceso de variación sin un plan, sin una guía clara ni un fin predeterminado: «No hay una dirección predefinida en el cambio que la testosterona inicia en mí» (Preciado, 2014, p. 188) - las cursivas son nuestras - Pero la inteligencia de Preciado es reconocer que este entregarse al

\section{LINGÜÍSTICA Y LITERATURA}

ISSN 0120-5587

165

E-ISSN 2422-3174

N. ${ }^{\circ} 80,2021,150-167$ 
Moléculas y postporno en Testo yonqui. Una lectura literaria de Paul B. Preciado

«placer de la multiplicidad» (Preciado, 2014, p. 88), este prometeísmo literario, sexual, teórico y político también es una de las caras de la producción de subjetividad y objetividad del capitalismo tardío. Si se nos permite el juego de palabras, Preciado reconoce que el prometeísmo también es un «promo-T-ísmo», un engranaje en la exigencia de la producción continúa de novedad: nuevos mercados, nuevos consumos, nuevos cuerpos. Testo yonqui, fiel a su intención de elaborar una problematización radical, no ofrece un camino sin claroscuros. 


\section{Referencias bibliográficas}

1. Blanchot, M. (1992). El libro que vendrá. Caracas: Monte Ávila.

2. Blanco, A. (2020). Literature and Politics in the Later Foucault. Boston: De Gruyer.

3. Brassier, R. (2017). El prometeísmo y sus críticos. En A. Avanessian y M. Reis (Eds..), Aceleracionismo. Estrategias para una transición hacia el postcapitalismo (pp. 201-220). Buenos Aires: Caja Negra.

4. Butler, J. (1997). The Psychic Life of Power: Theories in Subjection. Stanford: Stanford University Press.

5. Cassin, B. (1994). Nuestros griegos y sus modernos. Estrategias contemporáneas de apropiación de la Antigüedad. Buenos Aires: Manantial. 6. Conde Arroyo, P. (2019). El género narrativo de Testo yonqui. Aproximación a la deriva ensayística de Paul B. Preciado. Artes del Ensayo, 3, 191-214.

7. Deleuze, G. (1991). Posdata sobre las sociedades de control. En C. Ferrer (Ed.), El lenguaje literario (pp. 19-24), Montevideo: Nordan. 8. De Rosso, E. (2012). La línea de sombra: literatura latinoamericana y ciencia ficción en tres novelas contemporáneas. Revista Iberoamericana, 78(238-239),311-328.9. Foucault, M. (2018 [1983]). Una introducción a la vida no fascista, Revista de Frente.http://revistadefrente.cl/michel-foucault-unaintroduccion-a-la-vida-no-fascista-prologo-al-anti-edipo/.

10. Gelman Constantin, F. (2019). Formas de lo viviente en América Latina (1980-2018). Incursiones literarias en una escena biomédica [Tesis de doctorado, Universidad de Buenos Aires]. 11. Haraway, D. J. (1984). Ciencia, cyborgs y mujeres. La reinvención de la naturaleza. Madrid: Cátedra.

12. Hester, H. (2019). Xenofeminismo. Tecnologías de género y políticas de reproducción. Buenos Aires: Caja Negra.

13. Mendoza, J. J. (2011). Escrituras past_Tradiciones y futurismos del siglo XXI Buenos Aires: 17 Grises.

14. Montes, A. S. (2013). Políticas y estéticas de representación de la experiencia urbana en la crónica contemporánea. Buenos Aires: Corregidor.

15. Mosquera, M. E. (2020). Antropogenética del arte y la literatura. Interferencias entre estética y filosofía de la técnica. Estudios de Teoría Literaria, 9(18), 178-191.

16. Preciado, P. (2014 [2008]). Testo yonqui. Sexo, drogas y biopolítica. Buenos Aires: Paidós.

17. Preciado, P. (2019). Un apartamento en Urano. Crónicas del cruce. Barcelona: Anagrama.

18. Rodríguez, P. (2019). Las palabras en las cosas. Saber, poder y subjetivación entre algoritmos y biomoléculas. Buenos Aires: Cactus.

19. Schaeffer, J. (2001). Les genres littéraires d'hier à aujourd'hui. En M. Dambre \& M. Gosselin-Noat (Comps.) L'éclatement au genres au XXe siècle (pp. 11-20). Paris: Presses Universitaires de la Sorbonne Nouvelle.

20. Segdwick, E. (1997). Paranoid Reading and Reparative Reading; or, You're So Paranoid, You Probably Think This Introduction is About You. En E. Segdwick (Ed.), Novel Gazing. Queer Readings in Fiction (pp. 1-37), Londres: Duke University Press.

21. Shannon, C. E. (1948). A Mathematical Theory of Communication. The Bell System Technical Journal, 27(3), 379-423. 